\title{
Whole-Genome Sequencing and Analysis of Nutritional Traits in a Core Set of Ethiopian Teff (Eragrostis tef) Varieties
}

Nelzo C Ereful

NIAB

Huw Jones

NIAB

Nick Fradgley

NIAB

Lesley Boyd

NIAB

Hirut Assaye Cherie

Bahir Dar Institute of Technology

Matthew J Milner ( $\triangle$ matthew.milner@niab.com )

NIAB

\section{Research Article}

Keywords:

Posted Date: January 27th, 2022

DOI: https://doi.org/10.21203/rs.3.rs-1251010/v1

License: (1) This work is licensed under a Creative Commons Attribution 4.0 International License.

Read Full License 


\section{Abstract}

Background: Teff (Eragrostis teff) is a tropical cereal domesticated and grown in the Ethiopian highlands, where it has been a staple food of Ethiopians for many centuries. Food insecurity and nutrient deficiencies are major problems in the country, so breeding for enhanced nutritional traits, such as $\mathrm{Zn}$ content, could help to alleviate problems with malnutrition.

Results: To understand the breeding potential of nutritional traits in teff a core set of 24 varieties were sequenced and their mineral content, levels of phytate and protein, as well as a number of nutritionally valuable phenolic compounds measured in grain. Significant variation in all these traits was found between varieties. Genome wide sequencing of the 24 teff varieties revealed 3,193,582 unique SNPs and 897,272 unique INDELs relative to the teff reference var. Dabbi. Sequence analysis of two key transporter families involved in the uptake and transport of $\mathrm{Zn}$ by the plant led to the identification of 32 Zinc Iron Permease (ZIP) transporters and 14 Heavy Metal Associated (HMA) transporters in teff. Further analysis identified numerous variants, of which $14.6 \%$ of EtZIP and $12.4 \%$ of EtHMA variants were nonsynonymous changes. Analysis of a key enzyme in flavanol synthesis, flavonoid 3'-hydroxylase (F3'H), identified a T-G variant in the teff homologue Et_s3159-0.29-1.mrna1 that was associated with the differences observed in kaempferol glycoside and quercetin glycoside levels.

Conclusion: Wide genetic and phenotypic variation was found in 24 Ethiopian teff varieties which would allow for breeding gains in many nutritional traits of importance to human health.

\section{Background}

Teff(Eragrostisteff) is a tropical cereal that has its origins in the Ethiopian highlands, where it was domesticated and has been grown for thousands of years [1]. Globally teff is a minor cereal crop in terms of both production and planted area, with Ethiopia growing an estimated $90 \%$ of the annual global teffcrop on about three million hectares, which equates to about a quarter of the Ethiopian graincultivated area[2]. Compared to other cereals teff is considered a resilient crop.It can withstand adverse weather conditions,growing well at elevations between 1,800 and 2,200m above sea level, in regions where there is adequate rainfall[3]. Teffis a staple of Ethiopian diets,providing $11 \%$ of the per capita caloric intake and two-thirds of the average Ethiopians daily protein [4].

Teff is widely considered a healthy alternative to cereals such as wheat, maize and rice as it does not contain gluten,is high in slowly digestible starch, rich in calcium (Ca) and polyphenols[5,6]. However, levels of zinc ( $\mathrm{Zn}$ ) in the grain (in the range of $28-40 \mathrm{mg} / \mathrm{kg}$ ) areoften less than therecommended level of 40 $\mathrm{mg} / \mathrm{kg}$ necessaryto meet human nutritional requirements[1,7,8], withfurther fortification efforts being hampered by low Zn levels in many Ethiopian soils[1].

While breeding efforts to improve teffhave been ongoing in Ethiopia since the mid-1950s germplasm advancements have been slow, with only 20 new teffvarieties being released [3]. A better understanding of teff nutritional diversity and its genetic control could help drive nutritional gains for this crop. Recent 
advancements in our understanding of the genetics of teff include a fairly complete genome assembly, the release of gene models, as well as a number of RNASeq datasets which are all publicly available[9]. These allow for translation of knowledge on grain fortification from other species, supporting more rapid advancements in efforts to improve the nutritionalpotentialofteff[10-14].

Several gene families have been identified that support accumulation and transport of various heavy metals withinthe plant. The Zinc Iron Permease (ZIP) family of transporters, the Heavy Metal Associated (HMA) and Metal Tolerance Protein (MTP) families,and the Natural Resistance-Associated Macrophage protein (NRAMPs)family of transportershave all been shown to be integral in micronutrient transport in plants[15-19]. The transport of $\mathrm{Zn}$ from soil to seed can involve a number of these transporters, with $\mathrm{Zn}$ primarily being accumulatedwithin the seedembryo and aleuronelayer[20]. Inrice $\mathrm{Zn}$ uptake from the soil is thought to occur through the transporters OsZIP5and OsZIP9[21,22]. Others have suggested that many routes may be available to $\mathrm{Zn}$ uptake, as no single transporter is believed to be solely responsible for theuptake of $\mathrm{Zn}$ from the soil[23-27].Severaltransporter families have also been implicated in the transport of $Z n$ through the plantto the developing grains[16,28,29]. These include the HMA family and the ZIP family of transporters, both shown to be able to transport a broad range of metals[16,17,24,30], whichcan alsoincludethe transport of unwanted metals such as cadmium $(\mathrm{Cd})$ andlead $(\mathrm{Pb})$, both of which are detrimental to most plants and animals [15,17,24,30-32].

Otherfactors can also influence the $\mathrm{Zn}$ content in both plant leaves and grain.These include phytates, which readily bind cationssuch as calcium (Ca), iron (Fe) and $\mathrm{Zn}$,phosphate $(\mathrm{P})$ and phytate being found to correlate with $\mathrm{Zn}$ concentration in the grain of both wheat and rice [29,33].In wheat, nitrogen $(N)$ content has been found to positively correlate with $\mathrm{Zn}$ content in the grain [8].Recent work has shown that macronutrients such as N, P and sulphur (S), can also influence overall micronutrient content[34]. Thus, a holistic approach to nutrient enhancement is required to ensure adequate $\mathrm{Zn}$ supply in the human diet.

In this study we set out to understand the phenotypic variation of several nutritional traits inteff varieties commonly grown and consumed in Ethiopia. We used whole genome sequencing and single nucleotide polymorphisms (SNPs) to determine the genetic relationship between theseteff varieties. This genomic data was then used to look for relationships between the teff varieties andthenutritional traits to identify those varieties with optimal nutritional potential for breeding. In addition, SNPs within candidate genes underlying nutritional traits of interest were examined to determine linkages with the trait variation.

\section{Materials And Methods}

\section{Plant materialand flour preparation}

Twenty-four teff varieties (Additional file 1) weregrown in the main cropping season in 2018 to 2019 at the experimental station of AdetAgricultural Research Center, Ethiopia. Adet $\left(11^{\circ} 28 \otimes \mathrm{N}, 37^{\circ} 48 \otimes \mathrm{E} ; 2216 \mathrm{~m}\right.$ a.s.l) is located $42 \mathrm{~km}$ southwest of Bahir Dar, the capital city of the Amhara regional state, Ethiopia.

Agronomic and cultural practices recommended for teff production werewhich included application of 40 
$\mathrm{kg} \mathrm{N}$ and $60 \mathrm{~kg} \mathrm{P} \mathrm{O}_{5}$ per ha[35]. The soil at Adet is brown Nitosol. The lines which has been used in the study are publicly available lines in Ethiopia from the AdetAgricultural Research Center. The voucher specimen ID numbersare listed in additional file 1.

Teffwhole grains were milled to flour using a Laboratory Hammer Mill (Model: TPS-JXFM110, China) to a sieve size of $0.5 \mathrm{~mm}$, packed in polyethylene bags and stored at room temperature until analysed.

\section{Analyses of nutritional traits}

Analyses of all nutritional traits were undertaken at NIAB, UK. Analyses included assessment of elemental concentrations, phenolic compounds, phytate and $\mathrm{N}$ content.

Elemental concentrations were assessed using inductive coupled plasma mass spectrometry (ICPMS).ICP-MS was used to detect the beneficial micronutrients $\mathrm{Ca}, \mathrm{Cu}, \mathrm{Fe}, \mathrm{K}, \mathrm{Mg}, \mathrm{Mn}, \mathrm{Mo}, \mathrm{P}, \mathrm{S}, \mathrm{Se}, \mathrm{Ti}$, and $\mathrm{Zn}$, and the detrimental elements $\mathrm{Cd}$ and $\mathrm{Pb}$. Approximately $0.2-0.3 \mathrm{~g}$ of flour was digested in $5 \mathrm{~mL}$ of nitric acid (Sigma) overnight in a $7 \mathrm{~mL}$ bijou. The digested sample was transferred to a $50 \mathrm{~mL}$ beaker and heated to $115^{\circ} \mathrm{C}$ to remove the residual acid,after which $3 \mathrm{~mL}$ of $\mathrm{H}_{2} \mathrm{O}_{2}$ (Sigma) was added. After $\mathrm{H}_{2} \mathrm{O}_{2}$ reduction the remaining powder was dissolved in $15 \mathrm{~mL}$ of $\mathrm{ddH}_{2} 0$ and samples analysed on the ICP-MS using a Thermo-Fisher Scientific iCAP-Q equipped with CCTED (collision cell technology with energy discrimination). Three, independent technical replications were run for each teff flour sample.Possible soil contamination was identified where flour samples had greater than $100 \mathrm{mg} / \mathrm{kg}$ of $\mathrm{Fe}$, Al and possibly $\mathrm{Si}$, and/ or Ti above $1 \mu \mathrm{g} / \mathrm{g}[36,37]$.

$\mathrm{N}$ content was determined using Dumas analysis.Flour samples were dried at $104^{\circ} \mathrm{C}$ for three hours. One gram of flour was loaded according to the manufacturer's instructions (LecoTruMacN Dumas gas analyser) to determine $\mathrm{N}$ content. Dumas gas analysis was performed on three,technical replicate $1 \mathrm{~g}$ aliquots of flour from each variety.

Phenolic compounds were assessed using HPLC. Flour samples of approx. $2.5 \mathrm{~g}$ were extracted into 50 $\mathrm{ml}$ of ethanol-acetic acid (10\% $1 \mathrm{M}$ acetic acid $\mathrm{v} / \mathrm{v}$ ) under reflux conditions for 2 hours. Extracts were stored at $-20^{\circ} \mathrm{C}$ until analysed. The extracts were prepared for chromatography by centrifugation for two minutes at $13000 \mathrm{rpm}$, then filtrated through a $0.2 \mu \mathrm{m}$ filter. The compounds were separated using the Dionex Ultimate 3000 HPLC system. A $150 \mathrm{~mm}$ x $4.6 \mathrm{~mm} \times 5 \mu \mathrm{m} \times 100 \AA$ A Kinetix C18 column was used, with a gradient $0.1 \%$ formic acid /acetonitrile mobile phase running at $0.2 \mathrm{ml} /$ minute (gradient of 0.95 : 0.05 for 2 minutes, then $0.72 ; 0.28$ for 18 minutes, $0.00 ; 0.10$ for 28 minutes, and then held until 45 minutes) were used. The column effluent was monitored with a PDA detector between $200-600 \mathrm{~nm}$, with data recorded at $254 \mathrm{~nm}, 280 \mathrm{~nm}, 340 \mathrm{~nm}$ and $520 \mathrm{~nm}$.

Phytate was measured using the commercialMegazymePhytic Acid Assay Kit (Brey, Ireland)following the manufacturer'sinstructions with minor modifications.Approximately $100 \mathrm{mg}$ of flour was digested in 1.8 $\mathrm{mL} \mathrm{HCl}(0.66 \mathrm{M})$ in $2.2 \mathrm{~mL}$ tubes, placed in a rotator mixer overnight with a constant rpm of 20 , at room temperature. Three technical replicateswere applied for each flour sample. 


\section{Genomic DNA isolation and sequencing}

DNA was extracted from flour of the 24teffvarieties using Qiagen'sDNAeasy Kit as per the manufacturer's instructions, including RNase treatment. The same flour samples were used for DNA extraction as were used of nutrient trait analyses. DNA was shipped to Novogene (Cambridge UK) for Illumina Sequencing. Illumina libraries contained on average $350 \mathrm{bp}$ inserts and were sequenced using paired end technology. The estimated genome coverage of each teff variety wasat least 25X,based on an estimated size of the genome of $622 \mathrm{MB}$ [9]. Raw reads for all teffvarieties tested have been deposited with the ENA under the ArrayExpress accession E-MTAB-8827.

\section{Whole genome sequenceassembly and variant calling}

Paired-end sequence reads were provided by the sequencing service that had already undergone quality checks, including the removal of over-represented sequences, adapters, and reads with low-quality base scores (at Q > 20). No further analysis using FastQC[38]was thereforerequired. The paired-end reads were mapped against the indexed reference sequence of the teff variety Dabbi using BWA mem[9,39]. Output was piped to bam and sorted using SAMtools. PICARD tool was used to assign reads to a single Read Group (option: AddOrReplaceReadGroup). PCR duplicates were flagged using PICARD (option:

MarkDuplicates).A dictionary for the reference genome of contig names and sizes was also created using PICARD (option: CreateSequenceDictionary).Variants were identified using the Broad Institute Genome Analysis Tool Kit (GATK4; [40]). GATK (option: Haplotypecaller) was run for each teff variety, using its default parameters, to call variants between the reference Dabbi genome sequence and the variety sequence in both Variant Call Format (VCF) and Genomic VCF (option: -ERC GVCF) modes. Only variants with a quality score of $>20$ were considered. The variant SNPs were then analysed using gif 3 and bcftoolscsq[41] to determine whether the SNP was within a coding region, and whether the SNP was synonymous vs non-synonymous.

Using PLINK2 the VCF file was converted into PLINK binary format (bed, bim and fam). A phylogenetic tree was created using SNPhyloandthe biallelic SNPs identified across the 24 teff varieties [42]. A principal co-ordinate analysis (PCA) plot was constructed using the same biallelic SNPs and analysed using the R program SNPrelate[43]. FastStructure (with logistic prior, $\mathrm{K}=5$ ) was used to infer population structure within the 24 teff varieties using the same SNPs[44].

\section{Identification of zinc iron permease and heavy metal associated transporter familymembers in teff}

The Eragrostisteffgenome was searched using theBiomart toolinEnsembl plants (http://plants.ensembl.org/biomart/martview/) to identify predictedgenes that contain both the PFAM domain PF02535and Interpro ID IPR003689, or Interpro ID IPR027256.The PFAM domain PF02535and Interpro ID IPR003689 are used for the identification of ZIP transporter proteins and Interpro ID IPR027256for identification of HMA transporter proteins.Candidate ZIP transporter and HMA transporter

proteins in Arabidopsis and rice were also identified using Ensembl'sBiomart. The amino acid sequences of these candidate genes were aligned using MUSCLE as part ofMEGA X [45] using the default 
parameters and a phytogenic tree created using the Maximum Likelihood option, with 50 replications used for the determination of bootstrap values.

\section{Statistical analysis}

Micronutrient, $\mathrm{N}$ and phytate levels were tested for normality and homogeneity of variance using ShapiroWilk's test in R, which indicated a normal distribution. Two-way analysis of variance (ANOVA) was used to infer significance between teff varieties using the aov function and TukeyHSD commands in R. A least significant difference of $5 \%$ probability level was used as a post-hoc test to determine significance. Results were plotted using R ggplot2 and ggpubrpackages[46-48]. Correlations between micronutrients, $\mathrm{N}$ and phytate were calculated in $\mathrm{R}$ using the Spearman rank correlation (cor.test) or Kruskal-Wallis test for categorical variables[43].

All statistical analyses of phenolic compound levels were performed using Genstat v.16 (VSN International 2020). The levels of the phenolic compounds were analysed using a modified two-way ANOVA approach, General Linear Regression. The model applied was replicate by variety.Only comparisons having a F probability $<0.001$ were considered as statistically significant. The linear relationship between phenolic compound levels were measured using the Pearson correlation coefficient in Excel (Microsoft). Boxplots were generated using R ggplot2[47].

\section{Results}

\section{Comparison of nutritional traits in flour of twenty-fourteff varieties}

To understand the nutritional potential of 24teffvarieties (Additional file 1) currently grown and consumed in Ethiopiawe measured the levels ofa number of nutritional traits, comparing the relationship between these traits, and using genomic data to look at the genetic relationship between these 24 teffvarieties relative to these nutritional traits. The nutritional traits included elemental micronutrient (Fig. 1\&Additional file 2), nitrogen as a proxy for protein content (Fig. 2), phytate (Fig. 2) anda range of phenolic compounds (Additional file 3).

Significant variation between the 24teffvarietieswas found for all micronutrients tested (Additional file2) (p.val<0.001). Focus on elements essential for human health, $\mathrm{Zn}$ and Fe (Figure 1), showed Zn flour concentrations to range from 14.8 (var Etsub) to $29.2 \mathrm{mg} / \mathrm{kg}$ (var. Heber-1) and Fe to range from 22.6 (var Abay) to $684.25 \mathrm{mg} / \mathrm{kg}$ (var Yilmana)(Figure 1A\& B). Positive correlations were found betweenZn andCa, $\mathrm{Mg}, \mathrm{P}, \mathrm{S}$, and to a lesser extent $\mathrm{K}$, while negative correlations were found with $\mathrm{Cu}, \mathrm{Fe}, \mathrm{Mo}$ and $\mathrm{Se}$. A positive correlation was also seen between $\mathrm{Zn}$ and $\mathrm{Cd}$ (Suppl. Figure 1). No correlations were found between $\mathrm{Pb}$ or $\mathrm{Ti}$ and the other elements measured.

$\mathrm{Cd}$ is a toxic micronutrient, detrimental to human health. High levels of Cd were seen in many of the teffsamples tested, the highest levels of Cd beingfound in the variety Wellenkomi, having $40.7 \mu \mathrm{g} / \mathrm{kg}$. 
Only one of the teff varieties, var Magna, had Cd levels below the current EU limits for $\mathrm{Cd}$ in food products, being below $1 \mu \mathrm{g} / \mathrm{kg}(1 \mathrm{ppm})[49]$.

The Nlevels within the teffflours were measured as a proxy for protein content[50].Significant differences were found between the teff varieties, with $N$ values ranging from $1.3 \mathrm{~g} / 100 \mathrm{~g}$ in var. Ambo Toketo nearly $2 \mathrm{~g} / 100 \mathrm{~g}$ in var. Dagan teff(pval< 0.001)(Figure 2A). Using the standard conversion of 5.95 this would give protein content in the range of $7.79 \%$ to $11.71 \%[51]$.Apositive correlation was found between $\mathrm{Zn}$ content and $\mathrm{N}$ levels in the flours tested $(R=0.59 ; p$ val. 0.01 ; Figure $2 B)$ but not for Fe and $N(R=0.0096 ; p$ val 0.97; Figure 2C).

Significant differences werefound in phytate levels between the 24 teff varieties( $p$ val< 0.01 )(Figure 2D). The phytate levels ranged from $0.83 \mathrm{~g} / 100 \mathrm{~g}$ in var. Magna to $2.56 \mathrm{~g} / 100 \mathrm{~g}$ in var. Abay.No significant correlations were observed between phytate and $\mathrm{Zn}(\mathrm{R} 0.042 \mathrm{p}$ val. 0.84 ; Figure $2 \mathrm{E})$, but a significant negative correlation was found between Fe and phytate ( $R-0.54 \mathrm{p}$ val. 0.007 ; Figure $2 \mathrm{~F}$ ). There was no significant correlation between overall $P$ levels, measured via ICP-MS, and phytate $(R=0.29 ; p$ val. 0.18$)$.

Flour of the teff varieties werealso screened for19phenolic compounds(Additionalfile3).Significant differences ( $\mathrm{F} \mathrm{p} \mathrm{val.<0.001)}$ were found between the 24 teff varieties for 11 phenolic compounds, significant differences between teff varieties not being found for gallic acid. Seven phenolic compounds were not detected.These include cyanidin, cyanidin glycoside, delphinidin, delphinidin glycoside, flavone, pelagonidin and p-coumaric acid.

Kaempferol, quercetin, catechin and myricetin all belong to a group of phenolic compounds commonly known as flavonoids (Figure 3)[52]. The levels of kaempferol and quercetin were low in all the teffvarieties, the majority of these compounds being present as kaempferol glycoside and quercetin glycoside (Figure 4).The levels of kaempferol glycoside and quercetin glycoside ranged from 4.92 (var. Tseday) to $205.79 \mu \mathrm{g} / \mathrm{g}$ (var. Magna), and 0.46(var.Felagot) to $105.41 \mu \mathrm{g} / \mathrm{g}$ (var. Quncho), respectively. The levels of catechin ranged from 27.41 (var. Yilmana) to $183.19 \mu \mathrm{g} / \mathrm{g}$ (var. Tseday) (Figure 4).Catechin is derived from dihydroxyquercetin (Figure 3) and a precursor of proanthocyanidins, which are thought to give rice its red colouration [53].The levels of myricetin ranged from 0.82 (var. Were-kiyu) to 17.24 $\mu \mathrm{g} / \mathrm{g}(\mathrm{var}$.Dima) (Figure 4).

The levels of $t$-cinnamic acid ranged from $1.51 \mu \mathrm{g} / \mathrm{g}$ in var. Baset to $24.65 \mu \mathrm{g} / \mathrm{g}$ in var. Dukem.Cinnamic acid is a precursor of ferulic acid, which in turn gives rise to vanillic acid. A strong positive correlation was found between cinnamic and ferulic acids, and a lesser positive correlation with vanillic acid. However, the levels of vanillic acid were low in all 24 teff varieties (Additional file 3, Additional file 4).

Protocatechuic acid and gallic acid are synthesised from a side branch of the shikimate pathway that leads to the synthesis of folates and aromatic amino acids, including phenylalanine (Figure 3;[53]). The levels of protocatechuic acid ranged from $6.78 \mu \mathrm{g} / \mathrm{g}$ (var.Areka-1) to $44.78 \mu \mathrm{g} / \mathrm{g}$ (var. Felagot) (Additional file 3). The levels of gallic acid were low in all 24 teff varieties, ranging from $0.12 \mu \mathrm{g} / \mathrm{g}$ (var. Dima) to $0.97 \mu \mathrm{g} / \mathrm{g}$ (var. Ambo take (Figure 4). 
Pearson's correlation analyses were undertaken on the levels of each phenolic compound, phytate and Fe (Additional file 4).A strong, positive correlation was seen between cinnamic acid and ferulic acid ( $r=$ 0.78), fitting with the biochemical pathway (Figure 3), where cinnamic acid is a precursor of ferulic acid. Similarly, a positive association was seen between ferulic acid and vanillic acid $(r=0.51)$, vanillic acid sitting downstream of ferulic acid. However, positive correlations were also seen between ferulic acid and myricetin $(r=0.61)$, which may relate to their common precursor cinnamic acid, and between cinnamic acid and quercetin $(r=0.49)$ and quercetin glycoside $(r=0.50)$.

The precursors of kaempferol and quercetin, dihydrokaempferol and dihydroquercetin, exist in an equilibrium controlled by a flavonoid $3^{\prime}$-hydroxylase $\left(\mathrm{F}^{\prime} \mathrm{H}\right)$ enzyme which converts dihydrokaempferol to dihydroquercetin. This resulted in anegative correlations between kaempferol and quercetin $(r=-0.28)$ and kaempferol glycoside and quercetin glycoside $(r=-0.43)$; the majority of kaempferol and quercetin being present in the glycosylated state. This was reflected in positive correlations between kaempferol and quercetin glycoside $(r=0.62)$ and quercetin and kaempferol glycoside $(r=0.45)$.

Catechin is derived from dihydroquercetin and therefore competes for synthesis with quercetin. Consequently, a negative correlation was observed between the levels of catechin and quercetin $(r=$ -0.32). However, a positive correlation was seen between catechin and quercetin glycoside $(r=0.52)$. A positive correlation was also observed between catechin and kaempferol $(r=0.57)$ and a negative correlation with kaempferol glycoside $(r=-0.51)$.

In addition to positive correlations with kaempferol $(r=0.62)$ and catechin $(r=0.52)$, positive correlations were observed between quercetin glycoside and other phenolic compounds, including ferulic acid $(r=$ $0.65)$, myricetin $(r=0.56)$, cinnamic acid $(r=0.50)$. These correlations may indicate a positive feedback mechanism operating through the biosynthetic pathways leading to quercetin glycoside synthesis.

A negative correlation was found between gallic acid and salicylic acid $(r=-0.43)$, and between catechin and protocatechuic acid $(r=-0.44)$, while a positive correlation was observed between protocatechuic acid and Fe content $(r=0.40)$. No significant correlations were found between phytate levels and any of the phenolic compounds measured in this study (Additional file 4).

\section{Genetic relationship between thetwenty-four teffvarieties}

All 24 teff varieties were sequenced togreater than $25 X$ coverage. Sequences were compared to the referencevar.Dabbi across the whole genome. The varietiesdiffered by as few as 1.567 million SNPs in var. Areka-1relative to Dabbi, to as high as 2.372 millionSNPs in var. Yilmana (Additional file 5). There was also considerable variation in INDELs, with Yilmana showing the fewest INDELs at 343,257 and Wellenkomi the highest at 520,234. Overall,3,193,582 unique SNPs and 897,272 unique INDELs were found, containing a minimum allele frequency of 0.1 within the 24 varieties tested. Considering that the whole teffgenome is estimated to be $622 \mathrm{Mb}$ in size, the2.372 million variantsidentified in var.Yilmana relative to the reference var. Dabbi, equatesto roughly four variants in every kb of the genome. 
To understand how the 24 teffvarieties relateto each other a phylogenetic tree analysis(Figure 5A), a principal component analysis (PCA; Figure 5B), and a structure analysis (Figure 5C) were carried out using the genome wide SNP data. The phylogenetic tree and PCA separated the 24 teff varieties into 3 groups, however the structure analysis returned two groupings. In general, the teff varieties fell into similar groupings when comparing the phylogenetic tree and PCA, the exception being the varieties Negus and Kora, which fell on the same branch of the tree but in distinct PCA groups.

\section{Genetic variation underlying differences in $\mathrm{Zn}$ levels}

Zn concentrationswere overlaid on the PCA to see if a relationship between flour $\mathrm{Zn}$ levels and the teff variety groupings could be identified (Figure 5B).As no specific association between genetic grouping of teff varieties and $\mathrm{Zn}$ concentration were apparent, we chose to look at the genetic variation in specific gene families involved in Zn transport. Two gene families were selected. The ZIP (Zinc Iron Permease) family areinvolved in uptake of $\mathrm{Zn}$ from the soil and the HMA (Heavy metal associated) family of transportersare involved in movement of $\mathrm{Zn}$ from roots to seeds.

\section{Zinc Iron Permeasetransporter family in teff}

To identify putative ZIP family members the gene models of the Eragrostisteffvar. Dabbi sequence in Ensembl plants was searched using the PFAM domain PF02535 and Interpro ID IPR003689. This revealed 32 predicted genes in teff which contained theseprotein domains. As teff is a tetraploid species these 32 potential ZIP familymembers is comparable to the 15 in Arabidopsis and 17 in rice[30,54]. However, some of the predictedgenescould bepseudogenes. Onlysix of the 32 coding regionsidentified have a good ATGstart codon, and two of these six putative ZIP transporters lacked a stop codon. However, as this incomplete sequence data could be due to gaps in the reference var. Dabbiteff sequence we used all 32 putative ZIP sequences in subsequent analyses.

Phylogenetic analysis of the translated, amino acid sequences of the 32teffZIP transporterswas performed withmembers of the ZIP families from rice and Arabidopsis. Figure 6).Teff ZIP proteins showed closer linkages with rice ZIP proteins compared to Arabidopsis, both teff and rice being monocots.In most cases there were two teff genes for every rice ZIP gene, which is expected as teff is a tetraploid species, but not all 32 teff ZIP genes showed clear associations with genes found in riceor Arabidopsis, suggesting some divergence.Rice ZIP genes associated with more than two teff genes includedOsZIP8, which was associated with four teffgenes. Only one of the 32 teffZIP genes localized with OsZIP3, while three teffgenes colocalized with OsIRT2, as well as OsZIP10.

\section{Heavy Metal Associated transporter family in teff}

To identify putative HMA family members the gene models of the Eragrostisteffvar. Dabbi sequence in Ensembl plants was searched using the Interprodomain IPR027256. Fourteen HMA proteins were identified in teff compared to eight in Arabidopsis and nine in rice. Phylogenetic analysis of the translated, amino acid sequences of the 14teffHMA transporters was performed withmembers of the 
HMA families from rice and Arabidopsis(Figure 7). As 14 teff genes is less than expectedfor this tetraploid species, based on conservation of each of the eight core genes found in both rice and Arabidopsis, the teffDabbi reference sequence maybe incomplete with regards to this family of $\mathrm{Zn}$ transporters.In addition, five of 14predicted HMA genes in teff did not contain an ATG start codon, suggesting that some sequence is missing, or the gene models are incorrect.Four rice HMA proteins, OsHMA2, OsHMA5, OsHMA6 and OsHMA9, have two clear homologues with predicted teff HMA genes, but there does not appear to be any identified teff HMA gene aligning with OsHMA3, a major gene involved in Cd tolerance and sequestration[55].

\section{Identification of variants in ZIP and HMA proteins}

Numerous SNPs were found in both the ZIP and HMA tefffamilies of transporters (Additional files6, Additional file7). In the 32 EtZIPgenes a total of 355variants were identified in the coding regionsrelative to the reference var. Dabbi,this included frame shift mutations in twelve of the 32 genes( $3.4 \%$ of the total mutations)(Additional file 6). Most of the variantswere located in an intron (41.4\%), followed by synonymousvariants in the coding region (22.5\%), andthenby non-synonymous mutations that result in a change in the amino acid sequence (14.6\%).Many of the variants were conserved between the varieties, including a frameshift in both homologues of OsZIP9, with most of the varieties containing the mutated/truncated form of each gene.

In EtHMA transporters 298 variants were identified relative to var. Dabbi (Additional file 7). Most of the variants were again found in introns or represented synonymous mutations in the coding sequence (48\% and $16.4 \%$,respectively). Only two of the 14 teffHMA genes had frame shift variants. This included the predicted gene loci Et_s3091-2.42-1.mrna1 and Et_s3193-0.29-1.mrna1. The third most common variants werenon-synonymous mutations in the protein coding region (12.4\%).

\section{Genetic variation underlying differences in phenolic compounds}

Flavonoid $3^{\prime}$-hydroxylase $\left(\mathrm{F}^{\prime} \mathrm{H}\right)$ is a keyenzymein the conversion of dihydrokaempferol to dihydroquercetin $[53,56]$. To determine whether $F 3^{\prime} H$ in teffwas responsible for the differences seen between teff varieties in kaempferol glycoside and quercetin glycoside levels the amino acid sequence of the rice $\mathrm{F}^{\prime}{ }^{\prime} \mathrm{H}$ gene(Os10g0320100) was used to identify possible orthologs in teff. Using an e-value cut off of $1 \mathrm{e}-10$ five putative orthologs of OsF3'H were identified in the teff reference sequence of var. Dabbi:Et_s9738-1.8-1.mrna1, Et_s9399-0.5-1.mrna1, Et_s3159-0.29-1.mrna1,Et_s6352-0.10-1.mrna1 and Et_s15942-0.0-1.mrna1 (Suppl. Figure 2). Alignment of the amino acid sequences of thesefiveteff genes to their rice putative orthologs showed $58.74 \%$ to $78.57 \%$ identity. The two teff genes Et_s3159-0.291.mrna1and Et_s15942-0.0-1.mrna1clustered most closely with Os10g0320100 and were subject to further analysis.SNPs were identified between Et_s3159-0.29-1.mrna1 and Et_s15942-0.0-1.mrna1. Correlations between these SNPs and the levels of kaempferol glycoside and quercetin glycoside in the 24 teff varieties revealed a SNPin Et_s3159-0.29-1.mrna1that was strongly correlated with kaempferol glycoside and quercetin glycoside levels ( $p$ val<0.001). This SNP resulted in a T G substitution in the second intron ofEt_s3159-0.29-1.mrna1, and thereforedoes not directly change the coding sequence of 
the gene (Suppl. Figure 2). Teff varietiescontaining thewild-type (WT) "T" allele in the homozygous state had lower levels of kaempferol glycoside than teff varieties containing the mutant "G" SNP, and visa verse,while varieties with a heterozygous SNP had intermediary levels of the two glycosides (Figure 8). No furtherassociations were found between the other phenolic compounds measured and SNPs in any of the F3'H-type genes in teff.

\section{Discussion}

Teff is a staple crop for many Ethiopians, however, due to naturally low $\mathrm{Zn}$ levels in soils on which it is grown the grain does not meet the $\mathrm{Zn}$ needs of those who consume it[57]. Zn is essential for a healthy immune system and stimulates the activity of many different enzymes. The low level of $Z n$ in teff has therefore led to many Ethiopian children suffering from Zn deficiency [58].Fe is also an essential element, required for normal blood cell function [59], but has a low bioavailability, the small intestine not readily absorbing large amounts of Fe. However, a number of compounds have been shown to influence $\mathrm{Fe}$ absorption in the human gut, including phytate, kaempferol and quercetin [60-62].

To understand the breeding potential of teffforZn and Fe content, as well as several other nutritional factors,grain from 24 teffvarieties were assayed for a range of nutritional traits.Analysis of these 24 varieties showed significant variation in all the micronutrients tested, with atwofold difference in the amount of Zn beingobserved. However,even var. Heber-1, with $29.2 \mathrm{mg} / \mathrm{kg}$ of Zn, hadlevels below the recommended $40 \mathrm{mg} / \mathrm{kg}$ of $\mathrm{Zn}$ in flour [8]. This may be rectified by $\mathrm{Zn}$ fertilization of the soil, but future work would be required to understand how each variety responds to $\mathrm{Zn}$ soil supplements,given the complexity of $\mathrm{Zn}$ uptake and transportation to the grain.

No correlation was found between $\mathrm{Zn}$ and Fe levels in the grains, and is most likely due to different regulatory mechanisms and transporters involved in the movement of each ion through the plant $[16,28]$. The lack of identification of a homologue ofOs $H M A 3$, a gene associated with Cd tolerance and sequestration in rice, may also suggest an underlying cause for some of the high levels of $\mathrm{Cd}$ seen in the 24 teffflours. However, it should also be noted that other putative teffgenes, including a homolog of OsZIP1(Et_s3548-1.55-1.mrna1)which is involved in efflux of excess heavy metals, was one of the twelve teffgenes with a frame shift variant present in all the teffvarieties. This would suggest that multiple genes which sequester $\mathrm{Cd}$ in the roots, and keep it away from the grain,may not exist in teffor are non-functional in the modern teff varietiesassayed in this study[63].

Sequencing of the24 teffvarieties enabled the identification ofseveralvariants which could be used to develop markers for future breeding. Overall, there was a large amount of genetic variation between the varieties compared to the reference var.Dabbi. Although most of these variants were in non-coding regions or synonymous mutations, as seen in the analysis of the ZIP and HMA transporter families. The variation observed is not unexpectedas similar levels of variation have been observed in a core set of ricevarieties which were recently sequenced [64]. 
In rice, double mutants of OsZIP5 and OsZIP9have shown severe Zn deficiency symptoms, suggesting these two genes are the major route for $Z n$ into the rice plant[21,22]. However, mutants of either gene in isolation does not show major effects on $\mathrm{Zn}$ uptake. Mutations in two homologues of OsZIP9,including frame shifts,as well as a frame shift variant in a homologue of OsZIP5 in some varieties, would suggest that the route of $\mathrm{Zn}$ into teff, while compromised by these mutations, is not wholly dependent on the homologues of OsZIP5 and OsZIP9. Other transportersmaybe the major route for $\mathrm{Zn}$ intoteff plants. These other routes might also contribute to the high levels of $\mathrm{Cd}$ seen in many of the teff varieties. It has been shown that genes involved in $\mathrm{Mn}$ and Fe uptake can also transport $\mathrm{Cd}$ in vivo whereas high affinity Zn transporters do not appear to have this capability $[15,27,65-67]$.

Comparison of other nutritional traits,including nitrogen (as a proxy for protein), phytate and a number of phenolic compounds,also showed significant variation between the 24 teff varieties. The variation in the phenolicprofiles is of importance as some phenolicshave been found to alter Fe bioavailabilityand may therefore present a more effective strategy than Fe fortification for enhancing nutritional outcomes. It is often reported that phytate inhibits Fe bioavailability, so the negative correlation between Fe and phytate levels in teff could prove beneficial. While future research is requiredto determine whether elevated levels of phenolics that stimulate and inhibit Fe uptake in the human gut can help alleviate the anaemia seen in Ethiopian children [69], the significance of the SNP in the teff F3'H gene Et_s3159-0.29-1.mrna1, which explainsa large proportion of the variation in kaempferol glycoside and quercetin glycoside levels, suggest this might be a breeding target to improve Fe bioavailability in teff, as kaempferol glycoside is known to promote Fe absorption while quercetin glycoside inhibits Fe absorption in cell assays [60].In addition, phenolic compounds have also been found to influence other agronomic traits, including tolerance to both biotic and abiotic stress $[14,60,61,68]$.

With the considerable variation seen for the nutritional traits assessed in this study breeders are in a good position tobreed for enhanced nutritional value in teff. The genomic sequence information collected can be usedto identify and develop markers linkedto target genes and traits. We have yet to test the heritability of these traits and their stability over growing locations and seasons, butmarker-assisted selection, particularly within target genes,can now provide a feasible approach to breed for these nutritional traits in teff.

\section{Conclusion}

For many subsistence Ethiopian farming families teff is a major crop and source of calories. Yet, as shown in this study, levels of $\mathrm{Zn}$ are usually below recommended levels, while levels of Cd exceed EU limits. However, considerable phenotypic and genetic variation for a range of nutritional traits and the genes regulating their levels in planta, exists. This provides considerable potential to determine the relationship between these nutrition phenotypes and identify allelic variants that would allow breeding of new teff varieties with optimal nutritional potential.

\section{Abbreviations}


N: Nitrogen

Zn: Zinc

P: Phosphate

Fe: Iron

Cd: Cadmium

Pb: Lead

Ca: Calcium

S: Sulphur

$\mathrm{K}$ : Potassium

Mg: Magnesium

Mn: Manganese

Mo: Molybdenum

Se: Selenium

Ti: Titanium

Al: Aluminium

Si: Silicon

HPLC: High-performance liquid chromatography

PDA: Photo Diode Array

$\mathrm{HCl}$ : Hydrochloric acid

Vcf: Variant Call Format

EU: European Union

MTP: Metal Tolerance Protein

ZIP: Zinc Iron Permease

HMA: Heavy Metal Associated 
NRAMP: Natural Resistance-Associated Macrophage Proteins

SNP: Single Nucleotide Polymorphism

INDEL: Insertion or Deletion

ICP-MS: Inductively Coupled Plasma Mass Spectrometry

PCA:Principal Component Analysis

ENA: European Nucleotide Archive

\section{Declarations}

\section{Seeds collected:}

Permission to collect and analyse the milled seeds/flour of the teff varieties documented in this work was obtained from the Ethiopian government prior to research being conducted and samples being sent.

\section{Ethics approval and consent to participate:}

All the methods were carried out in accordance with relevant guidelines and regulations.

\section{Consent for publication:}

All authors consent to publication

\section{Availability of data and material:}

Sequencing Data is available at the ENA underArrayExpress accession E-MTAB-8827.

\section{Competing interests:}

The authors declare no competing interests.

\section{Funding:}

This work was supported by the Biotechnology and Biological Sciences Council (UK) BBSRC (grant BB/P027458/1) and pump priming grant (GCRF-SA-2020-NIAB). As well as the Cambridge Global Challenges fund. The funding bodies listed here played no role in the design of the study and collection, analysis, and interpretation of data, or in the writing of the manuscript.

\section{Authors' contributions:}

$M M, N F, N E$, and $H A C$ designed the experiments. MM, NF, NE, HJ performed the experiments. NE undertook the bioinformatic analyses. MM and LB undertook the statistical analyses of the data. The manuscript 
was written by MM and LB and subsequently revised by all authors. All authors have read and approved the final manuscript.

\section{Acknowledgements:}

The authors would like to thank the Adet Agricultural Research Center for providing the teff samples. The University of Nottingham school of Chemistry for running the ICP-MS samples for elemental content. Helen Appleyard and Marianna Rizzo at NIAB analytical services for analysis for N content analysis of the grains.

\section{References}

1. Baye K. Teff: nutrient composition and health benefits - IFPRI Publications - IFPRI Knowledge Collections [Internet]. Int. Food Policy Res. Inst. 2014 [cited 2020 Oct 27]. p. 20. Available from: https://ebrary.ifpri.org/digital/collection/p15738coll2/id/128334/

2. Lee H. Teff, A Rising Global Crop: Current Status of Teff Production and Value Chain. Open Agric J. Bentham Science Publishers Ltd.; 2018;12:185-93.

3. Fufa B, Behute B, Simons R, Berhe T. Strengthening the Tef Value Chain in Ethiopia. 2011.

4. Foodgrain consumption and calorie intake patterns in Ethiopia - IFPRI Publications - IFPRI Knowledge Collections [Internet]. [cited 2020 Oct 22]. Available from: https://ebrary.ifpri.org/digital/collection/p15738coll2/id/124853

5. Zhu F. Chemical composition and food uses of teff (Eragrostis tef). Food Chem. Elsevier Ltd; 2018;239:402-15.

6. Cheng A, Mayes S, Dalle G, Demissew S, Massawe F. Diversifying crops for food and nutrition security - a case of teff. Biol Rev Camb Philos Soc. Biol Rev Camb Philos Soc; 2017;92:188-98.

7. Abebe Y, Bogale, Alemtsehay Hambidge, K. Michael Stoecker BJ, Bailey K, Rosalind GS. Phytate, zinc, iron and calcium content of selected raw and prepared foods consumed in rural Sidama, Southern Ethiopia, and implications for bioavailability. J Food Compos Anal. 2007;20:161-8.

8. Cakmak I, Pfeiffer WH, McClafferty B. Biofortification of durum wheat with zinc and iron. Cereal Chem. John Wiley \& Sons, Ltd; 2010. p. 10-20.

9. VanBuren R, Man Wai C, Wang X, Pardo J, Yocca AE, Wang H, et al. Exceptional subgenome stability and functional divergence in the allotetraploid Ethiopian cereal teff. Nat Commun. Nature Research; 2020;11:1-11.

10. Nakandalage N, Nicolas M, Norton RM, Hirotsu N, Milham PJ, Seneweera S. Improving Rice Zinc Biofortification Success Rates Through Genetic and Crop Management Approaches in a Changing Environment. Front Plant Sci. 2016;7.

11. Klein MA, Grusak MA. Identification of nutrient and physical seed trait QTL in the model legume Lotus japonicus. Genome. 2009;52:677-91. 
12. Arora S, Cheema J, Poland J, Uauy C, Chhuneja P. Genome-wide association mapping of grain micronutrients concentration in aegilops tauschii. Front Plant Sci. Frontiers Media S.A.; 2019;10.

13. Oury FX, Leenhardt F, Rémésy C, Chanliaud E, Duperrier B, Balfourier F, et al. Genetic variability and stability of grain magnesium, zinc and iron concentrations in bread wheat. Eur J Agron. 2006;25:177-85.

14. Wright TIC, Gardner KA, Glahn RP, Milner MJ. Genetic control of iron bioavailability is independent from iron concentration in a diverse winter wheat mapping population. BMC Plant Biol. BioMed Central Ltd; 2021;21:1-13.

15. Milner MJ, Mitani-Ueno N, Yamaji N, Yokosho K, Craft E, Fei Z, et al. Root and shoot transcriptome analysis of two ecotypes of Noccaea caerulescens uncovers the role of NcNramp1 in Cd hyperaccumulation. Plant J. 2014;78.

16. Milner M, Kochian L. Investigating Heavy-metal Hyperaccumulation using Thlaspi caerulescens as a Model System | Annals of Botany | Oxford Academic. Ann Bot. 2008;102:3-13.

17. Hussain D, Haydon MJ, Wang Y, Wong E, Sherson SM, Young J, et al. P-type ATPase heavy metal transporters with roles in essential zinc homeostasis in arabidopsis. Plant Cell. American Society of Plant Biologists; 2004;16:1327-39.

18. Desbrosses-Fonrouge AG, Voigt K, Schröder A, Arrivault S, Thomine S, Krämer U. Arabidopsis thaliana MTP1 is a $\mathrm{Zn}$ transporter in the vacuolar membrane which mediates $\mathrm{Zn}$ detoxification and drives leaf Zn accumulation. FEBS Lett. No longer published by Elsevier; 2005;579:4165-74.

19. Dräger DB, Desbrosses-Fonrouge AG, Krach C, Chardonnens AN, Meyer RC, Saumitou-Laprade P, et al. Two genes encoding Arabidopsis halleri MTP1 metal transport proteins co-segregate with zinc tolerance and account for high MTP1 transcript levels. Plant J. John Wiley \& Sons, Ltd; 2004;39:425-39.

20. De Brier N, Gomand S V, Donner E, Paterson D, Smolders E, Delcour JA, et al. Element distribution and iron speciation in mature wheat grains (Triticum aestivum L.) using synchrotron X-ray fluorescence microscopy mapping and X-ray absorption near-edge structure (XANES) imaging. Plant Cell Environ. 2016;39:1835-47.

21. Yang M, Li Y, Liu Z, Tian J, Liang L, Qiu Y, et al. A high activity zinc transporter OsZIP9 mediates zinc uptake in rice. Plant J. Wiley; 2020;103:1695-709.

22. Tan L, Qu M, Zhu Y, Peng C, Wang J, Gao D, et al. Zinc transporter5 and zinc transporter9 function synergistically in zinc/cadmium uptake1. Plant Physiol. American Society of Plant Biologists; 2020;183:1235-49.

23. Milner MJ, Craft E, Yamaji N, Koyama E, Ma JF, Kochian L V. Characterization of the high affinity Zn transporter from Noccaea caerulescens, NcZNT1, and dissection of its promoter for its role in Zn uptake and hyperaccumulation. New Phytol. 2012;

24. Grotz N, Fox T, Connolly E, Park W, Guerinot M Lou, Eide D. Identification of a family of zinc transporter genes from Arabidopsis that respond to zinc deficiency. Proc Natl Acad Sci U S A. National Academy of Sciences; 1998;95:7220-4. 
25. Tiong J, McDonald G, Genc Y, Shirley N, Langridge P, Huang CY. Increased expression of six ZIP family genes by zinc $(Z n)$ deficiency is associated with enhanced uptake and root-to-shoot translocation of $\mathrm{Zn}$ in barley ( Hordeum vulgare). New Phytol. Blackwell Publishing Ltd; 2015;207:1097-109.

26. Palmgren MG, Clemens S, Williams LE, Krämer U, Borg S, Schjørring JK, et al. Zinc biofortification of cereals: problems and solutions. Trends Plant Sci. Trends Plant Sci; 2008. p. 464-73.

27. Curie C, Alonso JM, Le Jean M, Ecker JR, Briat JF. Involvement of NRAMP1 from Arabidopsis thaliana in iron transport. Biochem J. Portland Press Ltd; 2000;347:749-55.

28. Sperotto RA, Ricachenevsky FK, Williams LE, Vasconcelos MW, Menguer PK. From soil to seed: Micronutrient movement into and within the plant. Front. Plant Sci. Frontiers Research Foundation; 2014.

29. Magallanes-López AM, Hernandez-Espinosa N, Velu G, Posadas-Romano G, Ordoñez-Villegas VMG, Crossa $\mathrm{J}$, et al. Variability in iron, zinc and phytic acid content in a worldwide collection of commercial durum wheat cultivars and the effect of reduced irrigation on these traits. Food Chem. Elsevier Ltd; 2017;237:499-505.

30. Milner MJ, Seamon J, Craft E, Kochian L V. Transport properties of members of the ZIP family in plants and their role in $\mathrm{Zn}$ and Mn homeostasis. J Exp Bot. 2012;

31. Papoyan A, Piñeros $\mathrm{M}$, Kochian L V. Plant $\mathrm{Cd}^{2+}$ and $\mathrm{Zn}^{2+}$ status effects on root and shoot heavy metal accumulation in Thlaspi caerulescens. New Phytol. John Wiley \& Sons, Ltd; 2007;175:51-8.

32. Pence NS, Larsen PB, Ebbs SD, Letham DLD, Lasat MM, Garvin DF, et al. The molecular physiology of heavy metal transport in the Zn/Cd hyperaccumulator Thlaspi caerulescens. Proc Natl Acad Sci U S A. National Academy of Sciences; 2000;97:4956-60.

33. Stangoulis JCRR, Huynh B-LL, Welch RM, Choi E-YY, Graham RD. Quantitative trait loci for phytate in rice grain and their relationship with grain micronutrient content. Euphytica Springer; p. 289-94.

34. Kumar S, Kumar S, Mohapatra T. Interaction Between Macro- and Micro-Nutrients in Plants. Front Plant Sci. Frontiers; 2021;0:753.

35. Abewa A, Adgo E, Yitaferu B, Alemayehu G, Assefa K, Solomon JKQ, et al. Teff Grain Physical and Chemical Quality Responses to Soil Physicochemical Properties and the Environment. Agron 2019, Vol 9, Page 283. Multidisciplinary Digital Publishing Institute; 2019;9:283.

36. Cherney JH, Robinson DL. A Comparison of Plant Digestion Methods for Identifying Soil Contamination of Plant Tissue by TI Analysis1. Agron J. John Wiley \& Sons, Ltd; 1983;75:145-7.

37. Jones JB. Plant Tissue Analysis in Micronutrients. Micronutr Agric. John Wiley \& Sons, Ltd; 2018;477-521.

38. Andrews S. FastQC: a quality control tool for high throughput sequence data [Internet]. 2010. Available from: http://www.bioinformatics.babraham.ac.uk/projects/fastqc

39. Li H, Durbin R. Fast and accurate short read alignment with Burrows-Wheeler transform. Bioinformatics. 2009;25:1754-60. 
40. McKenna A, Hanna M, Banks E, Sivachenko A, Cibulskis K, Kernytsky A, et al. The genome analysis toolkit: A MapReduce framework for analyzing next-generation DNA sequencing data. Genome Res. Cold Spring Harbor Laboratory Press; 2010;20:1297-303.

41. Danecek P, McCarthy SA. BCFtools/csq: haplotype-aware variant consequences. Birol I, editor. Bioinformatics. Oxford University Press; 2017;33:2037-9.

42. Lee TH, Guo H, Wang X, Kim C, Paterson AH. SNPhylo: A pipeline to construct a phylogenetic tree from huge SNP data. BMC Genomics. BioMed Central; 2014;15:162.

43. Zheng X, Levine D, Shen J, Gogarten SM, Laurie C, Weir BS. A high-performance computing toolset for relatedness and principal component analysis of SNP data. Bioinformatics. Oxford Academic; 2012;28:3326-8.

44. Raj A, Stephens M, Pritchard JK. FastSTRUCTURE: Variational inference of population structure in large SNP data sets. Genetics. Genetics; 2014;197:573-89.

45. Kumar S, Stecher G, Li M, Knyaz C, Tamura K. MEGA X: Molecular Evolutionary Genetics Analysis across Computing Platforms.

46. Kassambara A. ggplot2. Based Publ Ready Plots [R Packag ggpubr version 02 5]. 2020;

47. Hadley W. Ggplot2: Elegrant graphics for data analysis. Springer; 2016.

48. Computing RF for S. R Core Team (2018). R: A language and environment for statistical computing [Internet]. 2018. Available from: https://www.r-project.org/

49. EUR-Lex - 02006R1881-20150521 - EN - EUR-Lex [Internet]. [cited 2020 Sep 12]. Available from: https://eur-lex.europa.eu/legal-content/EN/TXT/?uri=CELEX:02006R1881-20150521

50. Heathcote JG. The Protein Quality of Oats. Br J Nutr. Cambridge University Press; 1950;4:145-54.

51. Fujihara S, Sasaki H, Aoyagi Y, Sugahara T. Nitrogen-to-protein conversion factors for some cereal products in Japan. J Food Sci. J Food Sci; 2008;73.

52. Mbanjo EGN, Kretzschmar T, Jones H, Ereful N, Blanchard C, Boyd LA, et al. The Genetic Basis and Nutritional Benefits of Pigmented Rice Grain. Front. Genet. Frontiers Media S.A.; 2020. p. 229.

53. Mbanjo EGN, Kretzschmar T, Jones H, Ereful N, Blanchard C, Boyd LA, et al. The Genetic Basis and Nutritional Benefits of Pigmented Rice Grain. Front Genet. Frontiers Media S.A.; 2020;11:229.

54. Chen WR, Feng Y, Chao YE. Genomic analysis and expression pattern of OsZIP1, OsZIP3, and OsZIP4 in two rice (Oryza sativa L.) genotypes with different zinc efficiency. Russ J Plant Physiol. 2008;55:400-9.

55. Sasaki A, Yamaji N, Ma JF. Overexpression of OsHMA3 enhances Cd tolerance and expression of Zn transporter genes in rice. J Exp Bot. Oxford University Press; 2014;65:6013-21.

56. Lam PY, Lui ACW, Yamamura M, Wang L, Takeda Y, Suzuki S, et al. Recruitment of specific flavonoid B-ring hydroxylases for two independent biosynthesis pathways of flavone-derived metabolites in grasses. New Phytol. Blackwell Publishing Ltd; 2019;223:204-19.

57. Tessema M, De Groote H, D. Brouwer I, J.M. Feskens E, Belachew T, Zerfu D, et al. Soil Zinc Is Associated with Serum Zinc But Not with Linear Growth of Children in Ethiopia. Nutrients. 
2019;11:221.

58. Ayana G, Moges T, Samuel A, Asefa T, Eshetu S, Kebede A. Dietary zinc intake and its determinants among Ethiopian children 6-35 months of age. BMC Nutr. BioMed Central; 2018;4:30.

59. Sciences NA of S (US) and NRC (US) D of M. THE ROLE OF IRON IN HEMOGLOBIN SYNTHESIS. National Academies Press (US); 1958;

60. Hart JJ, Tako E, Glahn RP. Characterization of Polyphenol Effects on Inhibition and Promotion of Iron Uptake by Caco-2 Cells. J Agric Food Chem. American Chemical Society; 2017;65:3285-94.

61. Hart JJ, Tako E, Kochian L V., Glahn RP. Identification of Black Bean (Phaseolus vulgaris L.) Polyphenols That Inhibit and Promote Iron Uptake by Caco-2 Cells. J Agric Food Chem. 2015;63:5950-6.

62. Jin F, Frohman C, Thannhauser TW, Welch RM, Glahn RP. Effects of ascorbic acid, phytic acid and tannic acid on iron bioavailability from reconstituted ferritin measured by an in vitro digestion-Caco-2 cell model. Br J Nutr. Br J Nutr; 2009;101:972-81.

63. Liu XS, Feng SJ, Zhang BQ, Wang MQ, Cao HW, Rono JK, et al. OsZIP1 functions as a metal efflux transporter limiting excess zinc, copper and cadmium accumulation in rice. BMC Plant Biol. BioMed Central Ltd.; 2019;19:1-16.

64. Tanaka N, Shenton M, Kawahara Y, Kumagai M, Sakai H, Kanamori H, et al. Whole-Genome Sequencing of the NARO World Rice Core Collection (WRC) as the Basis for Diversity and Association Studies. Plant Cell Physiol. Oxford University Press; 2020;61:922-32.

65. Vert G, Grotz N, Dédaldéchamp F, Gaymard F, Guerinot M Lou, Briat JF, et al. IRT1, an Arabidopsis Transporter Essential for Iron Uptake from the Soil and for Plant Growth. Plant Cell. Oxford University Press; 2002;14:1223.

66. Lin YF, Hassan Z, Talukdar S, Schat H, Aarts MGM. Expression of the Znt1 zinc transporter from the metal hyperaccumulator noccaea caerulescens confers enhanced zinc and cadmium tolerance and accumulation to arabidopsis thaliana. PLoS One. Public Library of Science; 2016;11.

67. Milner MJ, Craft E, Yamaji N, Koyama E, Ma JF, Kochian L V. Characterization of the high affinity Zn transporter from Noccaea caerulescens, NcZNT1, and dissection of its promoter for its role in Zn uptake and hyperaccumulation. New Phytol. New Phytol; 2012;195:113-23.

68. Singh P, Arif Y, Bajguz A, Hayat S. The role of quercetin in plants. Plant Physiol Biochem. Elsevier Masson; 2021;166:10-9.

69. Hailu A. Ethiopian National Micronutrient Survey Report: September 2016. Ethiop Public Heal Institute, Minist Heal. 2016;

\section{Figures}




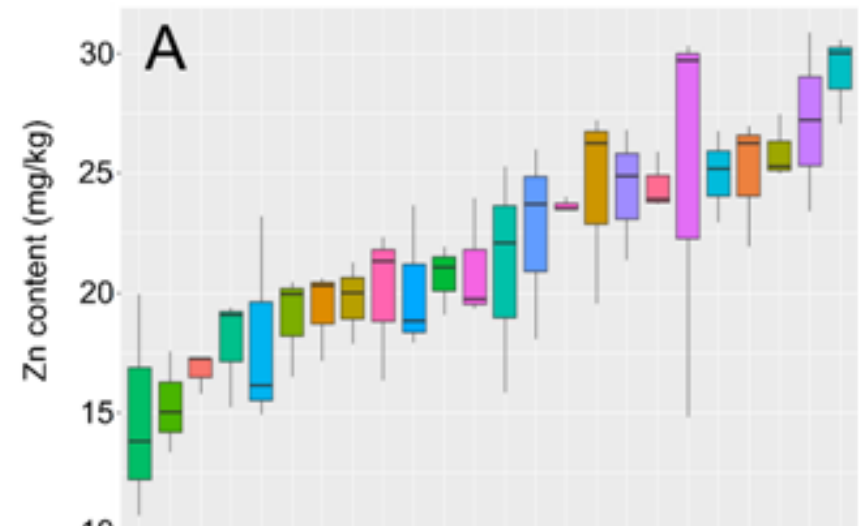

10
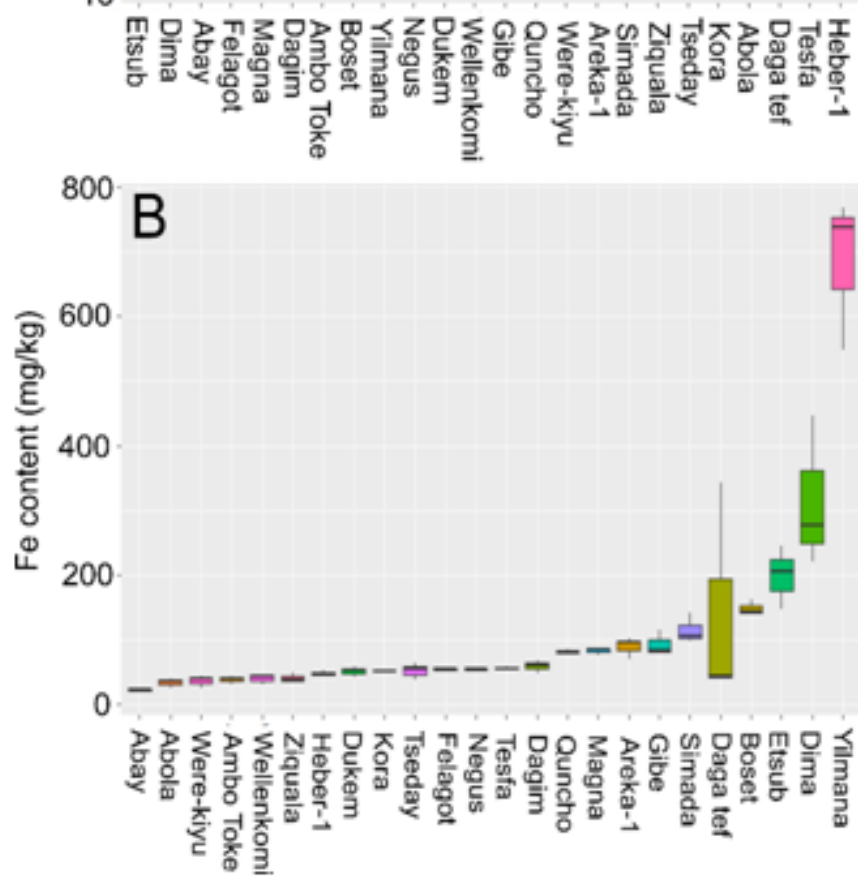

Figure 1

$\mathrm{Zn}$ and Fe levels in flour of 24 teff varieties grown at the Adet Research Agricultural Research Center in 2018/19. The box defines the upper and lower quartiles. The lines extending vertically, "whiskers", indicate variability outside the upper and lower quartiles. 

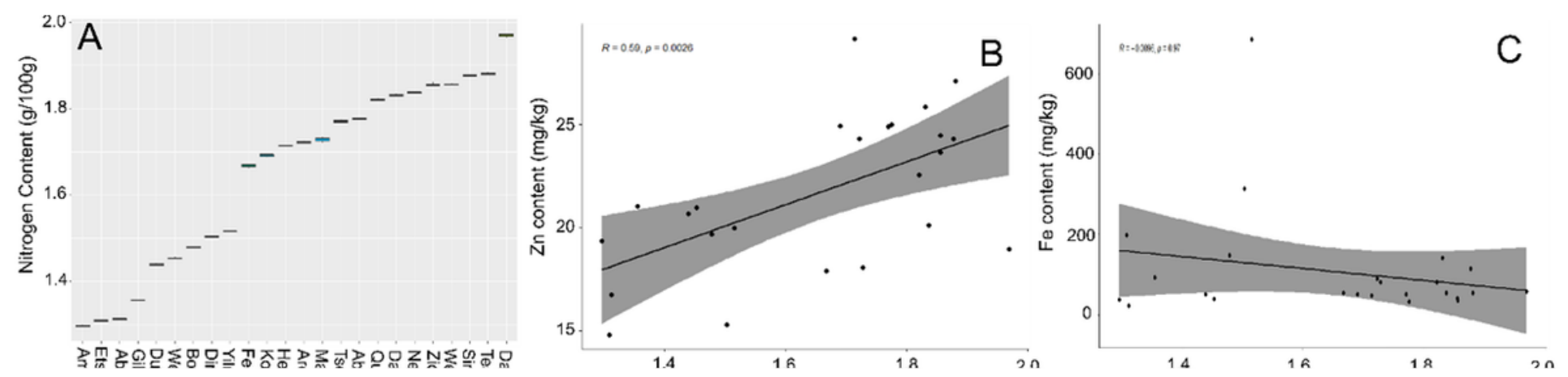

\section{Figure 2}

Relationship between Zn, Fe, nitrogen and phytate levels in 24 teff varieties. Nitrogen levels (A). Correlation between $\mathrm{Zn}$ and nitrogen content (B). Correlation between Fe and nitrogen content (C). Phytate levels (D). Correlation between Zn and phytate content (E). Correlation between Fe and phytate content (F). 
Shikimate Pathway

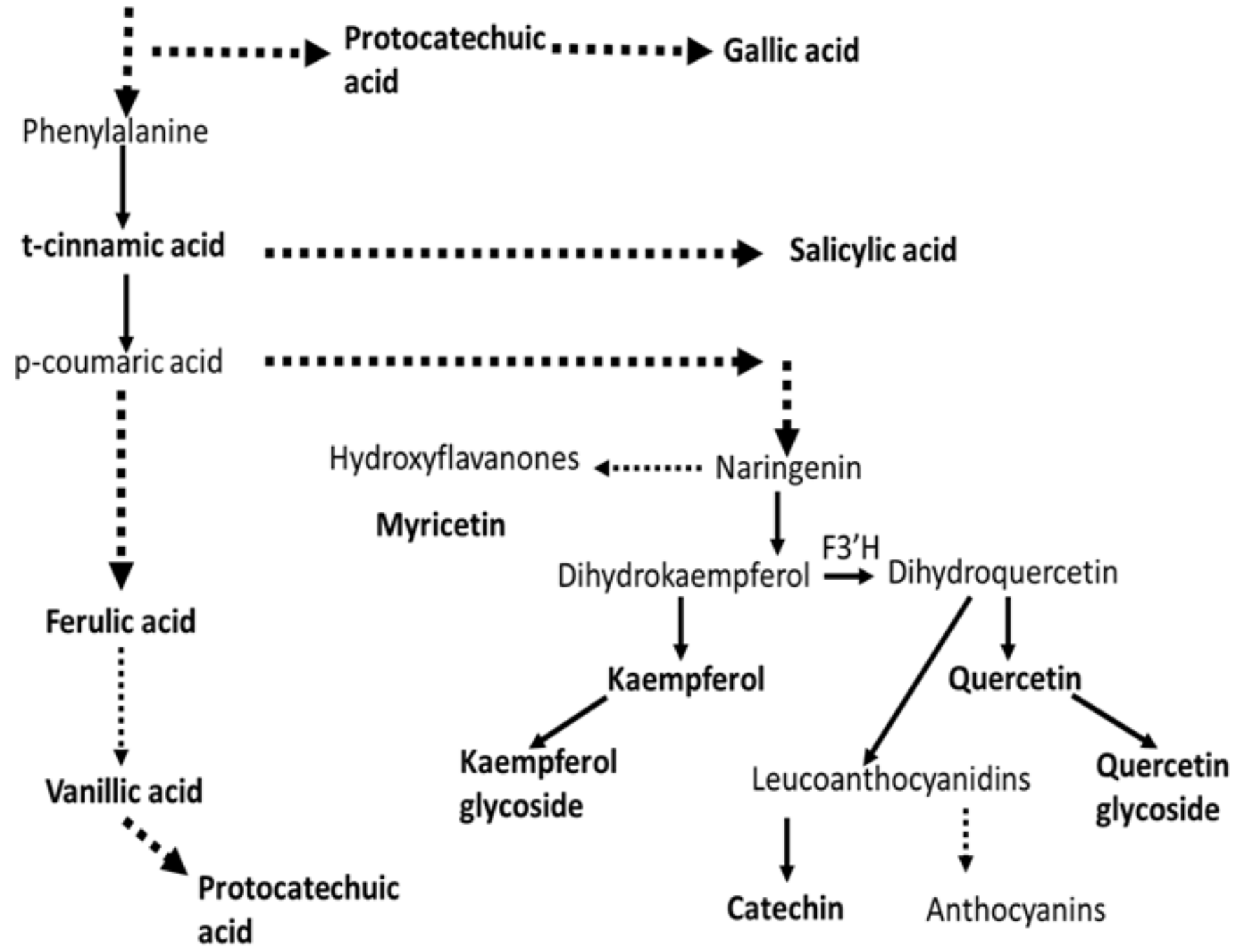

Figure 3

Biochemical pathway of selected phenolic compounds. The schematic shows the biochemical pathway relationship between the phenolic compounds measured in this study.Flavonoid $3^{\prime}$-hydroxylase $\left(F 3^{\prime} H\right)$ is a key enzyme in the conversion of dihydrokaempferol to dihydroquercetin. 


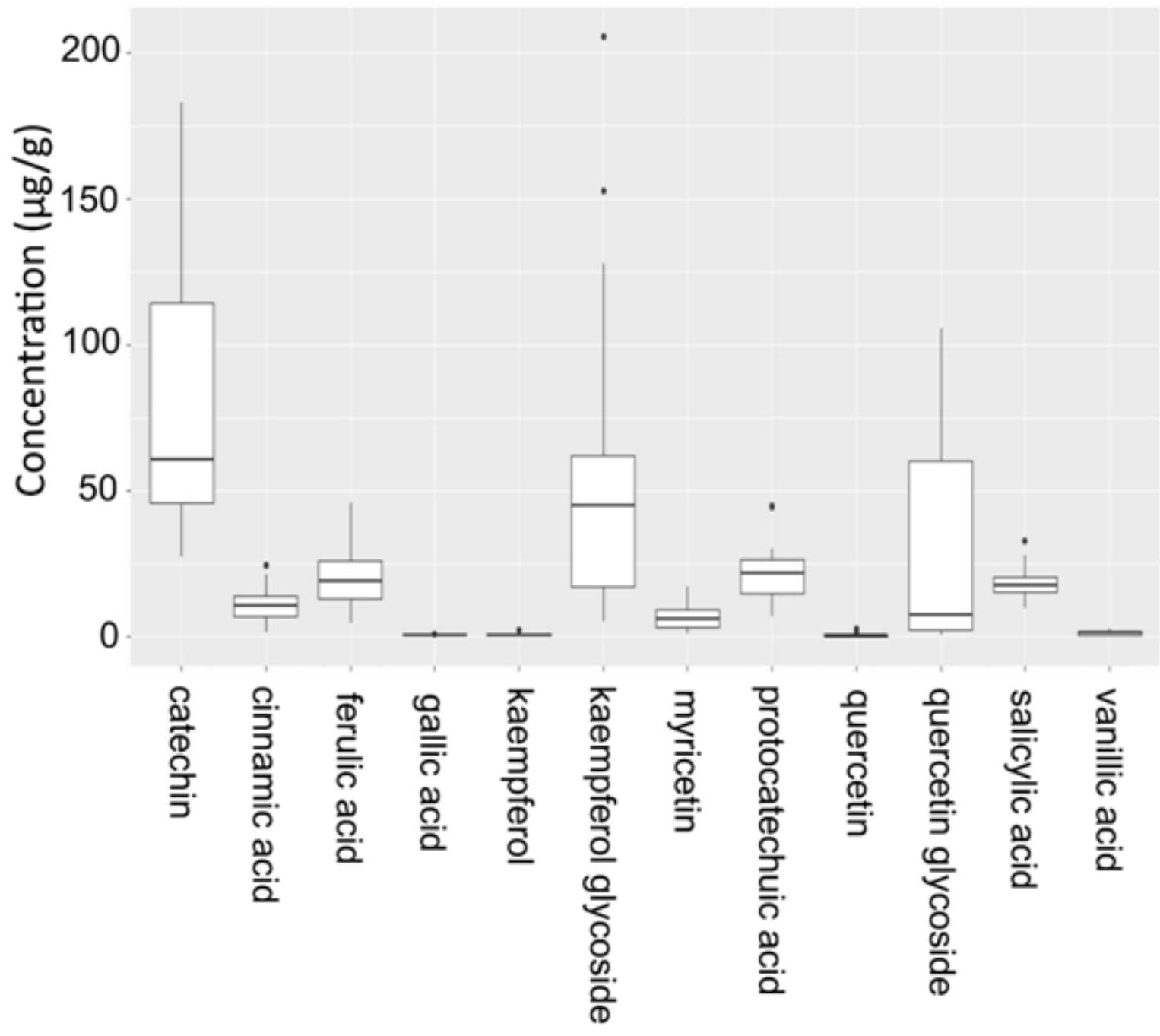

Figure 4

Levels of twelve phenols identified in the flours of 24 teff varieties. Each box shows the range of concentrations in $\mu \mathrm{g} / \mathrm{g}$ of 12 phenolic compounds measured in the 24 teff varieties. The box defines the upper and lower quartiles. The lines extending vertically, "whiskers", indicate variability outside the upper and lower quartiles, with points outside those lines, represented by dots, being considered outliers. 

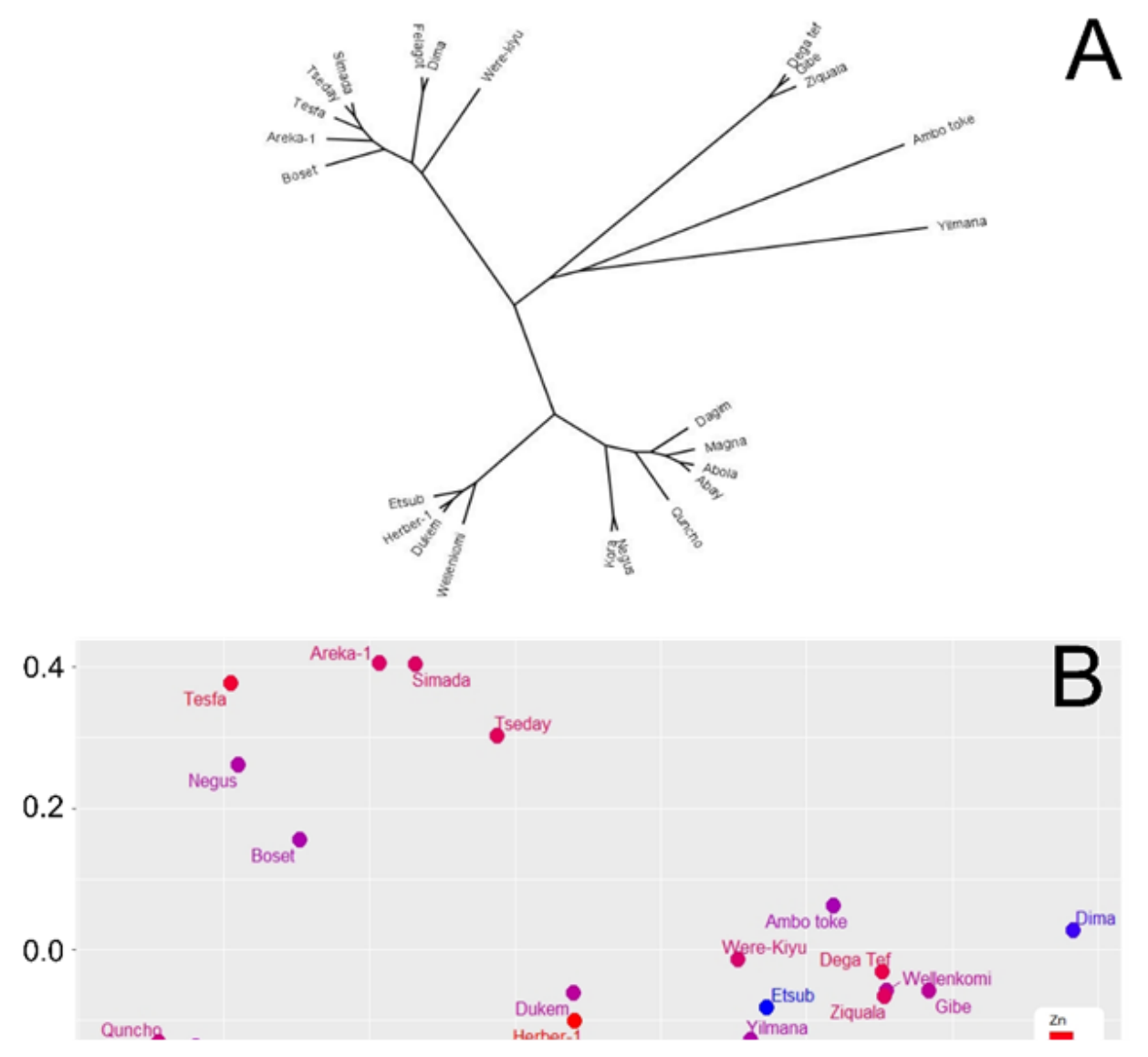

\section{Figure 5}

Population characteristics of the 24 sequenced teff varieties constructed using genome wide SNPs. (A) Phylogenetic tree, (B) PCA plot overlayed with grain Zn content, and (C) Population structure predicted using FastStructure. 


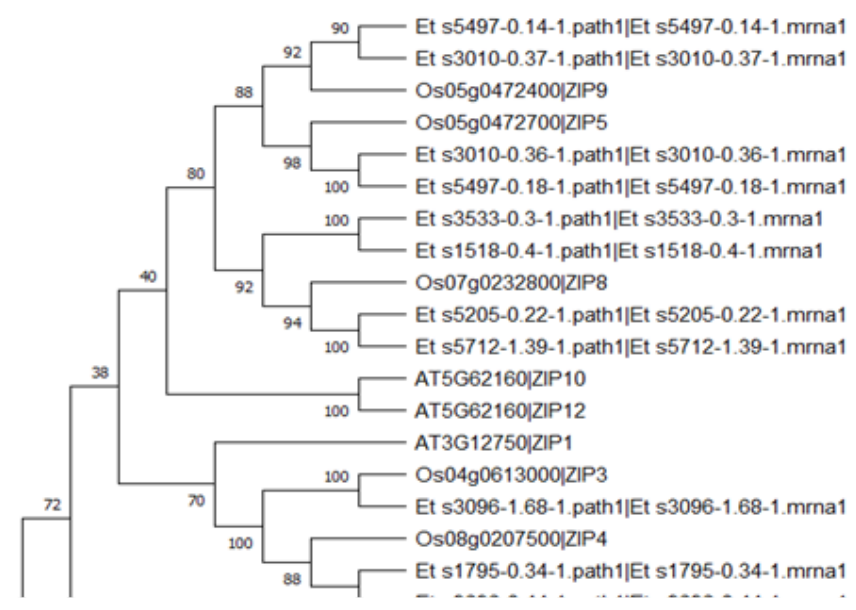

\section{Figure 6}

Phylogenetic tree of ZIP transporters. Shown is a maximum likelihood tree of Arabidopsis (At), rice (Os) and teff(Et) ZIP amino acid sequences.Values at each node are the calculated boot strap values from 50 iterations of the tree. 


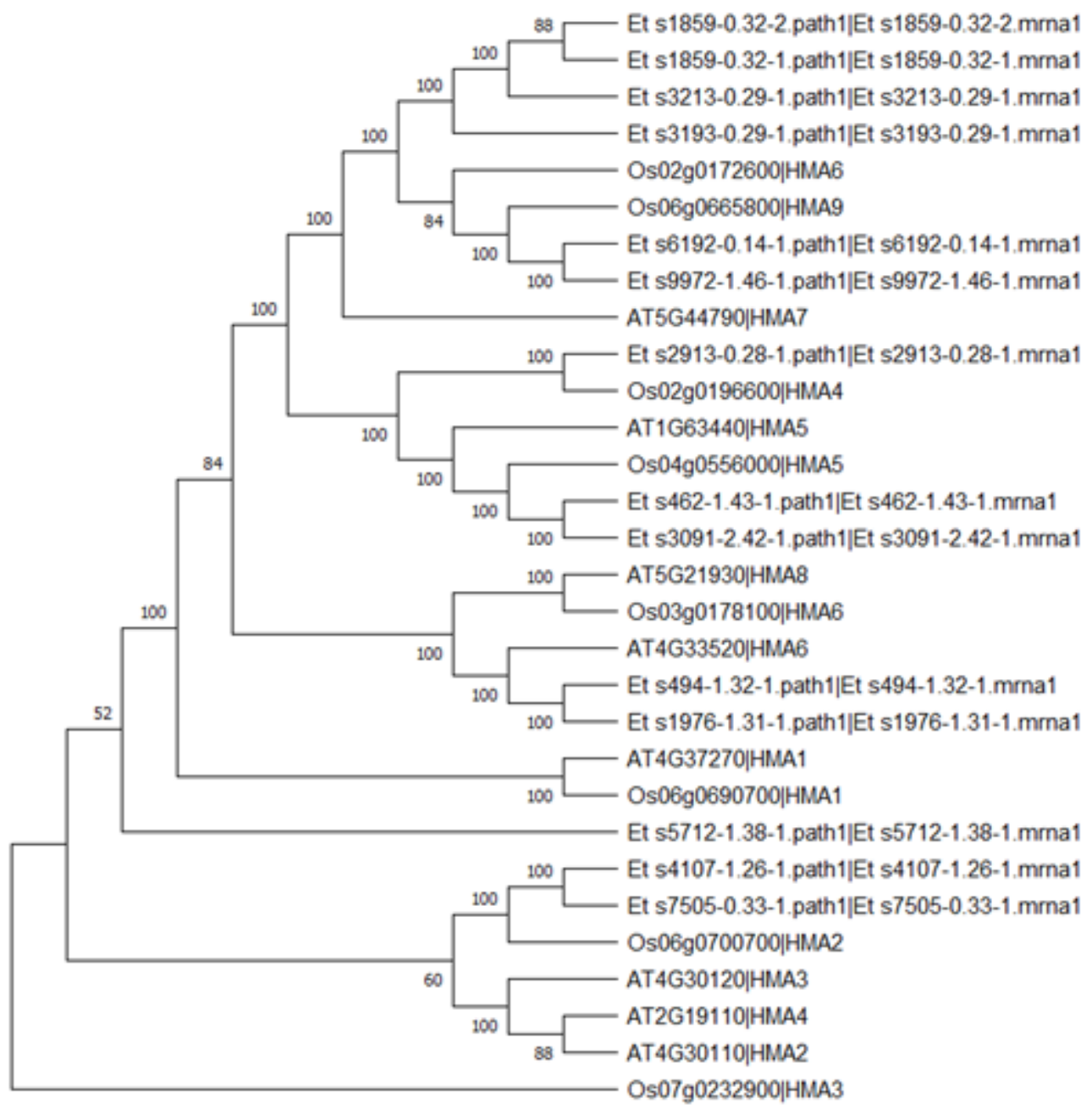

Figure 7

Phylogenetic tree of HMA transporters. Shown is a maximum likelihood tree of Arabidopsis (At), rice (Os) and teff(Et) HMA amino acid sequences. Values at each node are the calculated boot strap values from 50 iterations of the tree. 


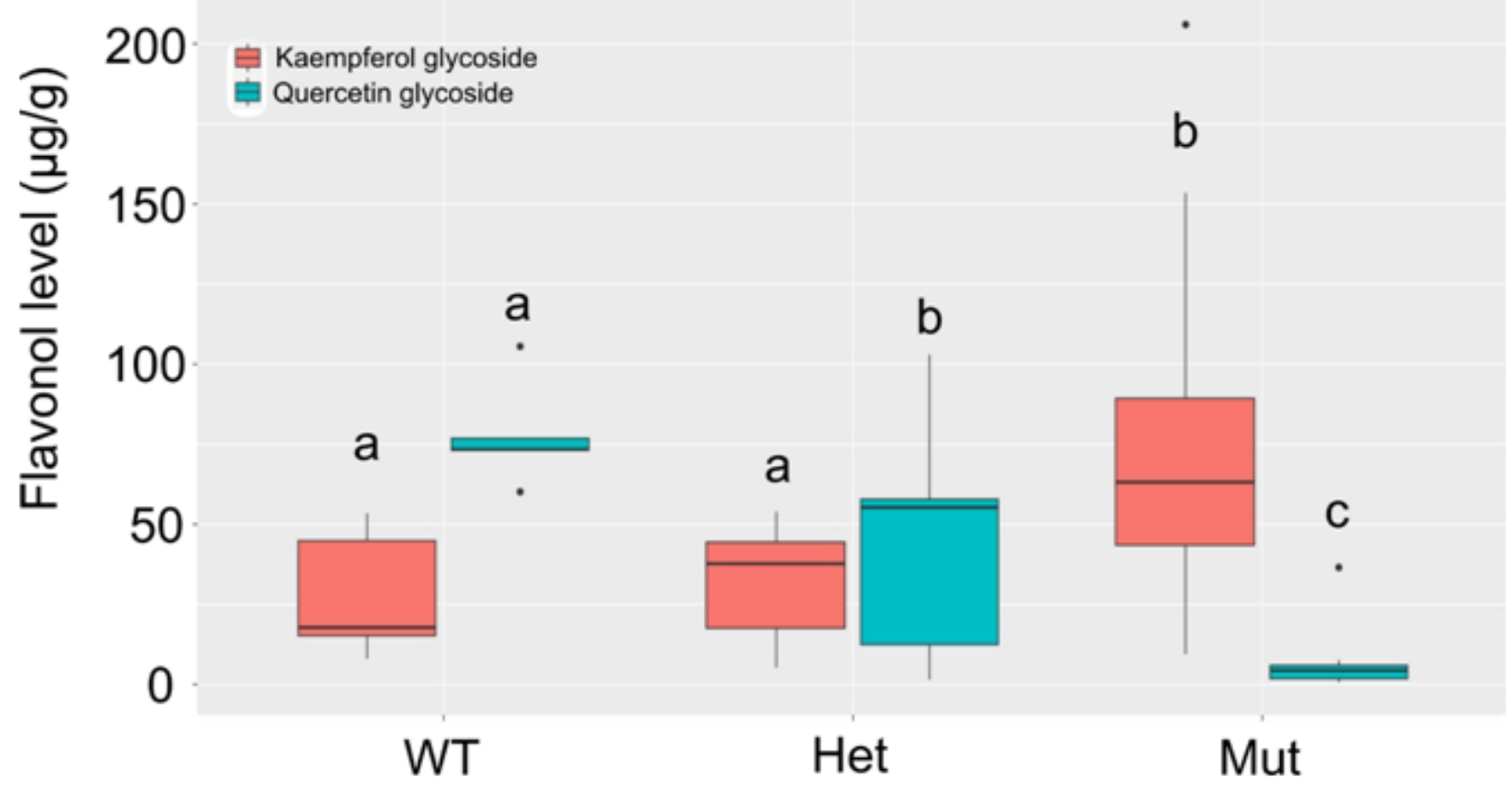

Figure 8

Haplotype analysis of a F3'H gene in teff. Kaempferol glycoside and quercetin glycoside levels in teff flours given the genotype of the T G mutation in the second intron of Et_s3159-0.29-1.mrna1. A different letter represents a significant difference $(p$ val<0.05) between genotypes for either kaempferol glycoside or quercetin glycoside.

\section{Supplementary Files}

This is a list of supplementary files associated with this preprint. Click to download.

- SupplFiguresfinal.docx

- Suppltables.xlsx 